\title{
Introduction the Minitrack on Social Information Systems
}

\author{
Rainer Schmidt \\ Munich University of \\ Applied Sciences \\ rainer.schmidt@hm.edu
}

\author{
Rainer Alt \\ Leipzig University \\ rainer.alt@uni-leipzig.de
}

\author{
Selmin Nurcan \\ University Paris 1 \\ Panthéon Sorbonne \\ nurcan@univ-paris1.fr
}

\section{Introduction}

Following the classical definition of an information system, users are an integral part as are procedures and (technological) infrastructures (e.g. [9]). Focusing on aspects of users has not only become part of the field of adoption, participation, and experience but also of the field of social informatics [1] and social computing [12] . While the former aim at conceptualizing and measuring causal relationships between the attributes of the information systems, the latter are more concerned with understanding and designing information systems in a cultural context and with applying social mechanisms. Referred to as social information systems [7], they differentiate from other information systems by their human element [4] and have received increased attention with the advent of social media, social software, and social platforms [1] [3].

Various forms of social information systems have emerged with online communities, collaborative technologies, blogs, wikis, and sites for crowdsourcing being among the most well-known. They can be differentiated on whether they support publishing (e.g., Twitter), sharing (e.g. SlideShare), discussing (e.g. Disqus), locating (e.g. Google Places), networking (e.g. Linkedin) or gaming (e.g. Playfish) [4].

Social information systems have profound implications on the way individuals communicate, be it in private or professional interactions, and the way economic processes are organized. For example, the so- called "Gig-economy" posits that crowdsourcing platforms have the power to change hierarchical coordination towards more market-like and fluid forms where individuals bring in their competencies for specific projects, i.e., "gigs". Social information systems may be seen as the new "glue" among individuals outside as well as inside organizations.
The relevance of this research field has triggered investigations exploring further areas of social information systems [6]. Besides technical aspects and requirements (e.g., Web 2.0 techniques, semantic interoperability, data analysis and fusion, social analytics), the integration of different stakeholders is an essential challenge for social information systems.

There is increasing research on social information systems and related subjects. For example, metatopics in Enterprise Social Network Research are identified in [10], and a literature review on enterprise social networks [11] and social collaboration analytics for enterprise social networks [8] also contribute towards fundamentals and future research topics. In [5] the authors provide a comparative analysis of the acquisition and assimilation of knowledge through social information and communication systems (SICS). Besides, an extensive review of the information systems research on online social networks is given in [2].

The increasing interest in social information systems motivated the creation of the Social Information Systems minitrack as part of the HICSS conference. In the following, the foundations and characteristics of social information systems shall be explained. Then the papers selected for publication with the social information systems minitrack shall be presented.

\section{Objective of the Minitrack}

The advances in research make it promising to further improve the exchange of ideas, concepts, technologies, empirical results, etc. on social information systems.

The objective of the minitrack "Social Information Systems" is to promote the scientific exchange on social information systems. The minitrack shall 
explore how social information systems are designed, implemented, operated and improved. It shall also contribute to the understanding regarding the interaction with their environment and the impact on economic coordination structures.

The minitrack seeks papers that explore how social information systems are designed, implemented, operated and integrated.

\section{Accepted Papers}

Three papers were submitted to the Minitrack "Social Information Systems". Two of them were accepted after a rigorous review process with two phases.

In the paper "The Structure of Social Documents", Susan P. Williams, Julian Mosen, and Petra Schubert create the foundations for the use of social documents as digital traces of collaborative activity in enterprise collaboration platforms. They start with a review of related research. Furthermore, by empirically analyzing social documents, they identify key concepts and structures. Based on this they create the Social Document Ontology (SocDOnt) expressing the generic structure of social documents. The paper extends previous research both at the micro-level and macro- level. Using these constructs, a more nuanced and granular analysis of social documents to understand collaborative activity in enterprise collaboration platforms is achieved.

Vivek Kumar Singh, Saurav Chakraborty, and Arjun Kadian investigate in their paper "Effect of Knowledge Sharing on Open Source Contribution: A Multiplatform Perspective" how different types of knowledge sharing affect an individual's contribution towards open source projects. The authors refine the taxonomy by two subtypes - strong explicit knowledge sharing and weak explicit knowledge sharing, depending on the extent of interpersonal interaction required for knowledge transfer. From a multi-platform perspective, the authors map the user identities across two platforms and analyze monthly panel data. The results demonstrate that both strong and weak explicit knowledge sharing has positive association with open source contribution.

\section{Acknowledgments}

We wish to thank all authors who submitted papers to the Social Media Minitrack for having shared their work with us, the many participants creating fruitful discussion, as well as the members of the Social Media Minitrack Program Committee, who made a remarkable effort in reviewing the submissions. We also thank the organizers of HICSS 2020 for their help with the organization of the event.

\section{References}

[1] Alt, R. and Reinhold, O. "Social Customer Relationship Management: Fundamentals, Applications, Technologies". Springer, Cham, 2020.

[2] Berger, K., Klier, J., Klier, M., and Probst, F. "A Review of Information Systems Research on Online Social Networks.". CAIS, vol. 35, 2014, pp. 8.

[3] Bühler, J. and Bick, M. "Name it as you like it? Keeping pace with social media something". Electronic Markets, vol. 28, no. 4, 2018, pp. 509-522.

[4] Iyer, E.K. "Uniqueness of Social in the Overall SMAC Stack". In G. Heggde and G. Shainesh, eds., Social Media Marketing. Springer Singapore, Singapore, 2018, pp. 3749.

[5] Limaj, E. and Bernroider, E.W. "A comparative analysis of social information and communication systems for supporting potential absorptive capacity". In Social Knowledge Management in Action. Springer, 2017, pp. 61- 79 .

[6] Schlagwein, D., Schoder, D., and Fischbach, K. "Social Information Systems: Review, Framework, and Research Agenda". ICIS 2011 Proceedings., 2011.

[7] Schmidt, R., Alt, R., and Nurcan, S. "Social Information Systems". Proceedings of the 52nd Hawaii International Conference on System Sciences., 2019, pp. 2642-2646.

[8] Schwade, F. and Schubert, P. "Social Collaboration Analytics for Enterprise Social Software: A Literature Review". practice, vol. 2, 2018, pp. 3.

[9] Turban, E., Leidner, D., Mclean, E., and Wetherbe, J. "Information Technology for Management". John Wiley \& Sons, 2008.

[10] Viol, J. and Hess, J. "Information systems research on enterprise social networks-a state-of-the-art analysis". Multikonferenz Wirtschaftsinformatik (MKWI), vol. 1, no. 1, 2016, pp. 351-362.

[11] Wehner, B., Ritter, C., and Leist, S. "Enterprise social networks: A literature review and research agenda". Computer Networks, vol. 114, 2017, pp. 125-142.

[12] Zhang, D., Mao, W., Zhan, J., and Zeng, D. "Editorial: Special Issue on Social Computing and E-Business". Information Systems and E-Business Management, vol. 10, pp. 161-163. 